\title{
Carbon monoxide prevents hepatic mitochondrial membrane permeabilization
}

Cláudia SF Queiroga ${ }^{1,2}$, Ana S Almeida ${ }^{1,2}$, Paula M Alves ${ }^{1,2}$, Catherine Brenner ${ }^{3}$, Helena LA Vieira ${ }^{1,2^{*}}$

\begin{abstract}
Background: Low concentrations of carbon monoxide (CO) protect hepatocytes against apoptosis and confers cytoprotection in several models of liver. Mitochondria are key organelles in cell death control via their membrane permeabilization and the release of pro-apoptotic factors.

Results: Herein, we show that CO prevents mitochondrial membrane permeabilization (MMP) in liver isolated mitochondria. Direct and indirect approaches were used to evaluate MMP inhibition by CO: mitochondrial swelling, mitochondrial depolarization and inner membrane permeabilization. Additionally, CO increases mitochondrial reactive oxygen species (ROS) generation, and their scavenging, by ß-carotene addition, decreases CO protection, which reveals the key role of ROS. Interestingly, cytochrome c oxidase transiently responds to low concentrations of $\mathrm{CO}$ by decreasing its activity in the first $5 \mathrm{~min}$, later on there is an increase of cytochrome c oxidase activity, which were detected up to $30 \mathrm{~min}$.
\end{abstract}

Conclusion: $\mathrm{CO}$ directly prevents mitochondrial membrane permeabilization, which might be implicated in the hepatic apoptosis inhibition by this gaseoustransmitter.

\section{Background}

Carbon monoxide $(\mathrm{CO})$ is usually considered a harmful and toxic molecule due to its high affinity to heme proteins. However, recent evidences show that low doses of $\mathrm{CO}$ can be cytoprotective, presenting several biological properties, namely, anti-apoptosis, anti-proliferation, anti-inflammation and vasodilatation [1]. Furthermore, $\mathrm{CO}$ is an endogenous product of heme degradation by heme-oxygenase $(\mathrm{HO})$, generating free iron and biliverdin as by-products. In fact, $\mathrm{HO}$ system is essential for tissue response to diverse pathological contexts, aiming at restoring and/or maintaining cellular homeostasis [2].

In hepatocytes and/or liver models, $\mathrm{CO}$ appears to act as an anti-apoptotic molecule. By stimulating ATP production, $\mathrm{CO}$ activates p38 MAPK signalling, preventing apoptosis in human hepatocytes [3]. CO rescues mice from fulminant hepatitis, presenting a marked reduction of TNF-alpha-induced apoptosis [4] or via NO generation [5]. In primary cultures of rat hepatocytes, $\mathrm{CO}$ limits cytotoxicity induced by glucose deprivation through

\footnotetext{
* Correspondence: hvieira@itqb.unl.pt

'Instituto de Biologia Experimental e Tecnológica (IBET), Apartado 12, 2781901 Oeiras, Portugal

Full list of author information is available at the end of the article
}

suppression of ERK MAPK activation [6]. In an endotoxic shock model, $\mathrm{CO}$ protects hepatocytes from apoptosis by augmenting iNOS expression [7]. It is also described that superoxide anion-induced apoptosis is inhibited by $\mathrm{CO}$ via limiting JNK activity [8]. CO treatment protects hepatocytes from cell death by inducing NF-kB activation, which is dependent on ROS generation, since inhibition of ROS generation (via antioxidant addition or by using respiratory deficient cells) reverses CO-induced cytoprotection [9]. Among all publications showing $\mathrm{CO}$ as anti-apoptotic molecule in hepatic model, only Kim and colleagues [10] have mentioned the involvement of mitochondria. $\mathrm{CO}$ protects hepatocytes from TNF-alpha/Actinomycin D-induced apoptosis by activating NF-kB, which is associated with a reduction in cytochrome $\mathrm{c}$ release from mitochondria [10]. However, no data demonstrate the direct role of $\mathrm{CO}$ into isolated liver mitochondria.

Mitochondria play a key role in the intrinsic pathways of apoptosis. Many pro-apoptotic factors are confined in the inter-membrane space, and upon mitochondrial membrane permeabilization (MMP) these factors are released into the cytosol and cell death becomes an irreversible process [11]. MMP marks a point of no return 
in the apoptotic intrinsic pathways by activating both caspase-dependent and caspase-independent mechanisms. The rupture of mitochondrial membrane also leads to the functional impairment of mitochondria, bioenergetic and redox crisis with ATP depletion and strong oxidative stress [12]. Therefore, mitochondria become a crucial target to modulate cell death in several models.

Based on the following facts: (i) $\mathrm{CO}$ is an anti-apoptotic molecule in several hepatic models, hepatocytes and/ or liver and (ii) mitochondria are central executers of cell death process, via the mitochondrial membrane permeabilization (MMP); we explored the direct effect of $\mathrm{CO}$ into isolated liver mitochondria (MMP modulation) and the involvement of ROS in this process. MMP was assessed by mitochondrial depolarization, inner membrane permeabilization and mitochondrial swelling.

\section{Results}

\section{Assessment of $\mathrm{CO}$ toxicity and establishment of optimal} $\mathrm{CO}$ concentration in isolated liver mitochondria

In order to evaluate the toxicity of carbon monoxide (CO) on isolated liver mitochondria, swelling and depolarization assays were performed with different doses of $\mathrm{CO}(10$ to $500 \mu \mathrm{M})$. Up to $100 \mu \mathrm{M}$ and for 30 minutes, $\mathrm{CO}$ is not able to trigger mitochondrial swelling. However $\mathrm{CO}$ triggers swelling at concentrations of 250 and $500 \mu \mathrm{M}$ (Figure 1A), indicating that at higher concentrations this gas induces mitochondrial damage. Because mitochondrial depolarization is an earlier event compared to swelling, lower concentrations of $\mathrm{CO}$ have induced lost of $\Delta \Psi \mathrm{m}$, only at $10 \mu \mathrm{M}$ there is no depolarization induction (Figure 1B). Pre-treatment with 10,50 or $100 \mu \mathrm{M}$ of $\mathrm{CO}$ for 15 minutes partially prevents mitochondrial swelling induced by calcium (Figure 1C). Since $10 \mu \mathrm{M}$ presents the highest protection and does not induce mitochondrial depolarization, this concentration is the optimal one to be used in all other assays.

\section{CO inhibits mitochondrial membrane permeabilization (MMP) in isolated liver mitochondria}

$\mathrm{CO}$ partially inhibits mitochondrial swelling (Figure 2A) when liver isolated mitochondria were exposed to $10 \mu \mathrm{M}$ of $\mathrm{CO}$ during 15 minutes at room temperature prior to addition of calcium to induce MMP (Figure 2A and 2C, left panel) and of atractyloside, a ligand of ANT that prevents $\mathrm{ADP} / \mathrm{ATP}$ translocation and induces its pore forming function (Figure $2 \mathrm{~A}$ and $2 \mathrm{C}$, right panel) [13-15]. Swelling quantification analysis was performed at different time points for calcium or atractyloside because of their different mode of action and kinetics (Figure 2C, left and right panel). Loss of $\Delta \Psi \mathrm{m}$, or mitochondrial depolarization, induced by atractyloside or calcium was also prevented by prior addition of $\mathrm{CO}$ at $10 \mu \mathrm{M}$ (Figure 2B) and quantification analysis was done (Figure 2D) for calcium (left panel) and for atractyloside (right panel). Changes in the inner membrane permeability (the opening of a large channel for molecules up to $\sim 800 \mathrm{Da}$ ) were assessed by an enzymatic assay based on the accessibility of citrate synthase, which is a soluble matrix enzyme [16]. The atractyloside induction of inner membrane permeabilization is partially prevented by $\mathrm{CO}$ (Figure 3). Due to the nature of this enzymatic assay, the quantification of the effect has to be done by calculating the slopes of the different curves over time, which were normalised relatively to $\mathrm{Ca}^{2+} 5 \mu \mathrm{M}$ (Table 1). CO pre-treatment decreases the slope compared to $\mathrm{Ca}^{2+}$ $5 \mu \mathrm{M}(85 \%$ vs 100\%) and Atra $300 \mu \mathrm{M}(81 \%$ vs 145\%). This reduction demonstrates $\mathrm{CO}$ delay in the induction of inner membrane permeabilization. Taken together, $\mathrm{CO}$ acts directly on mitochondria in order to limit their membrane permeabilization, shown by its prevention of swelling, depolarization and inner membrane permeabilization.

\section{ROS are important molecules for CO prevention of MMP} in liver mitochondria

Mitochondrial generated reactive oxygen species (ROS) are described as imperative signalling molecules for CO biological functions [17-20]. Thus, the role of ROS in CO-induced protection in isolated liver mitochondria was also evaluated. First, it was verified whether $\mathrm{CO}$ increases ROS generation in isolated liver mitochondria in a dose-response manner and this generation is limited by pre-treatment with $ß$-carotene (Figure 4A). To disclose ROS role in this system, their level augmentation was prevented by treating mitochondria with $\beta$-carotene prior to $\mathrm{CO}$ addition and MMP induction. Indeed, CO inhibition of mitochondrial swelling (Figure 4B), depolarization (Figure 4C) and inner membrane permeabilization (Figure 4D and Table 2) were, at least, partially prevented by the antioxidant $\beta$-carotene. Thus, at mitochondrial level, ROS appear to be important signalling molecules for $\mathrm{CO}$ mode of action during inhibition of mitochondrial membrane permeabilization.

\section{Low concentrations of $\mathrm{CO}$ transiently prevents cytochrome c oxidase (COX) activity}

Major intracellular sources of ROS are the oxidative phosphorilation complexes. Moreover, accordingly to the literature, $\mathrm{CO}$ is described to prevent cytochrome $\mathrm{c}$ oxidase (COX) activity [17]. Thus, $\mathrm{CO}$ direct effect on the COX activity was assessed in isolated liver mitochondria. $\mathrm{CO}$ at $10 \mu \mathrm{M}$ transiently prevents COX activity up to 10 minutes, while 30 minutes later the effect is inverted; CO slightly accelerates COX activity (Figure 5). 


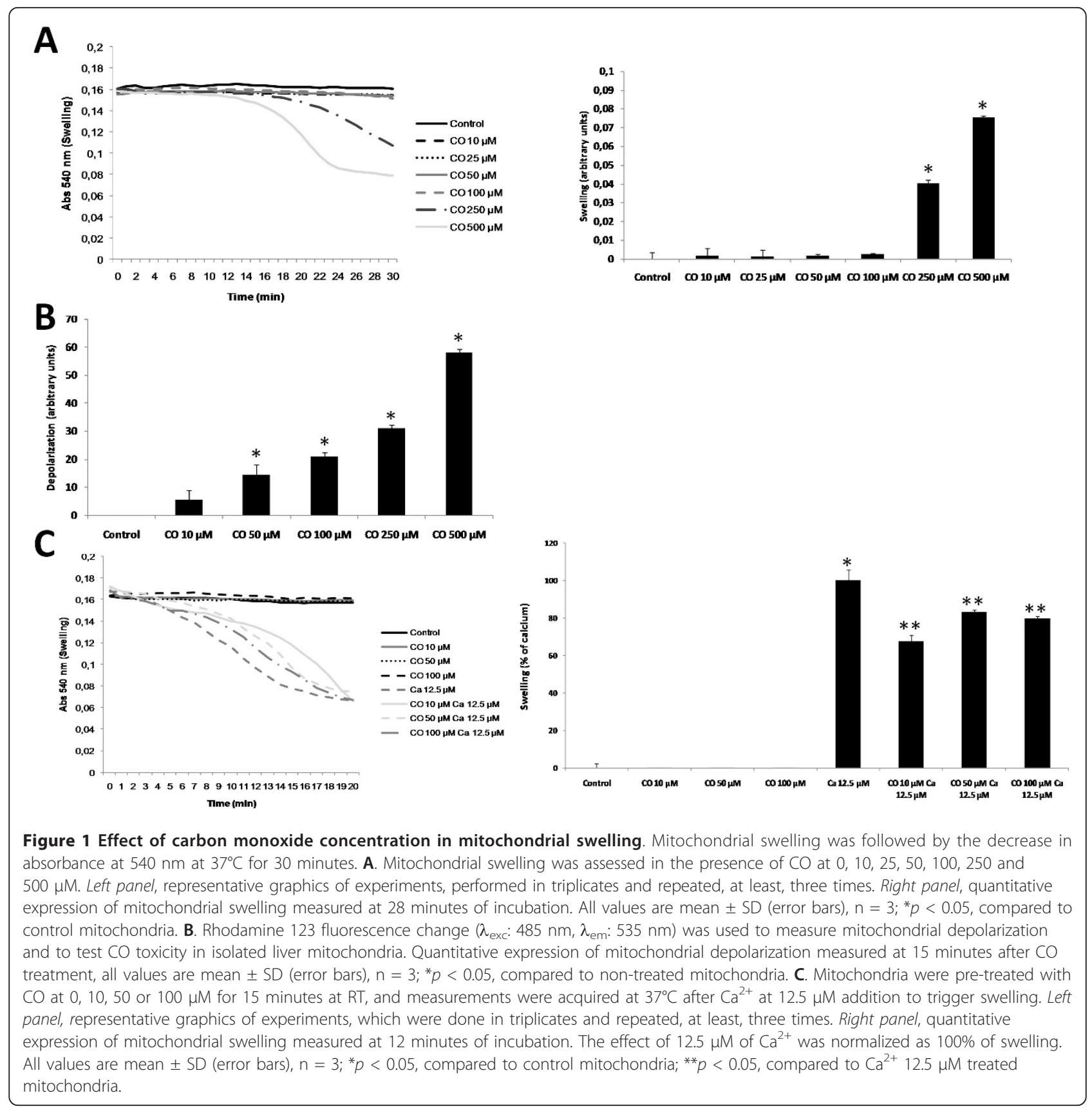

\section{Discussion}

Carbon monoxide has been described to be involved in protection of hepatocytes against cell death. Kim and colleagues [10] have demonstrated that CO decreases Bcl-2 family proteins translocation into mitochondria, limiting cytochrome c release into the cytosol [10]. Despite the crucial role of mitochondria in cell death control and the potent anti-apoptotic property of $\mathrm{CO}$ in hepatocytes, the direct effect of $\mathrm{CO}$ in isolated liver mitochondrial membrane permeabilization has never been reported before. Herein it is shown that low doses of this gaseous molecule prevent mitochondrial membrane permeabilization. Recently, we have shown that CO limits mitochondrial membrane permeabilization in non-synaptic mitochondria isolated from rat brain cortex [21], which was accompanied by inhibition of cytochrome c release from mitochondria and by glutathionylation of adenine nucleotide translocase (ANT). In this cerebral model, CO protects astrocytes against cell death and ROS generation appears to be important for this pathway [21]. Furthermore, in other systems, it is generally recognized that several $\mathrm{CO}$ 


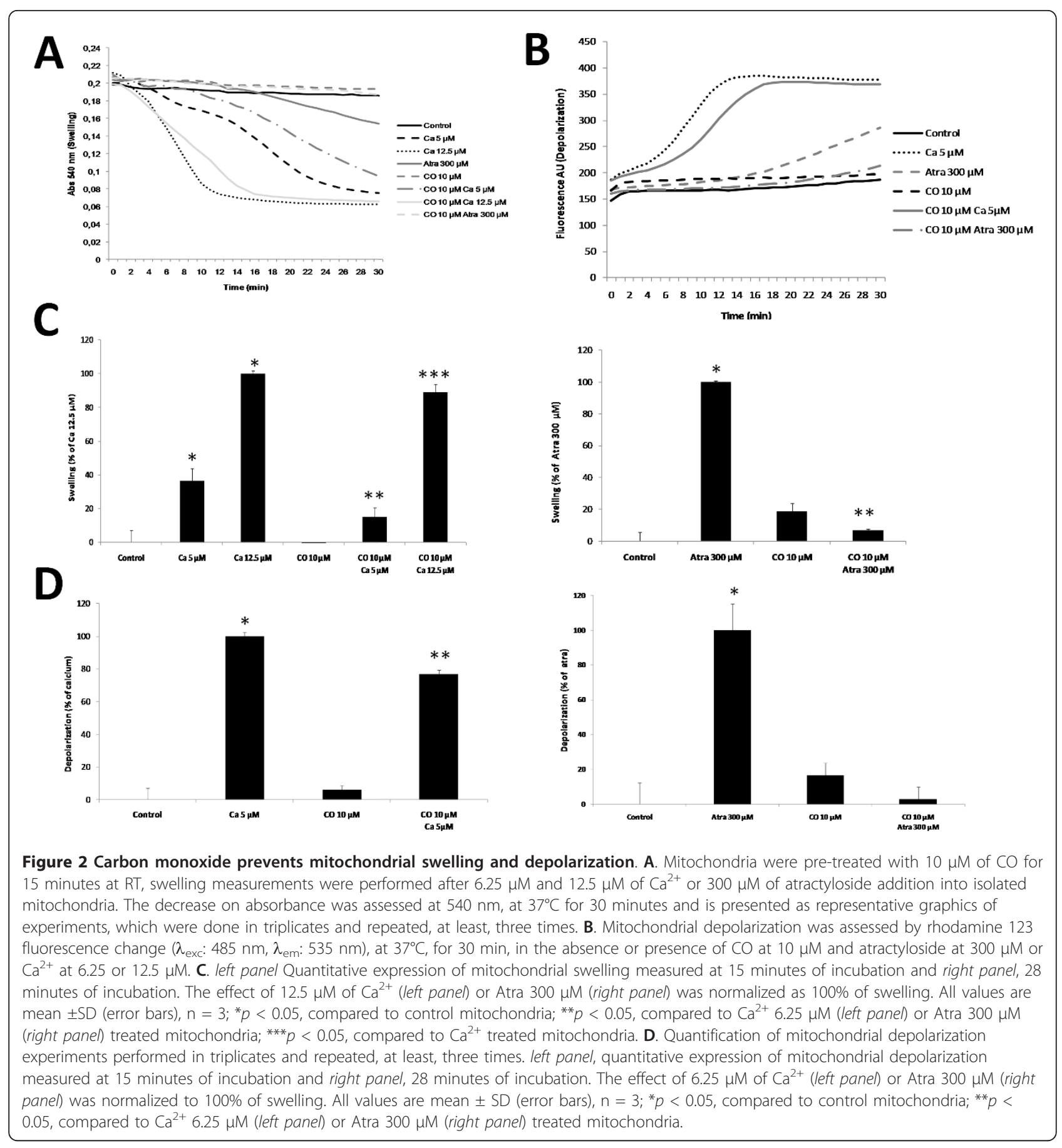

biological functions are dependent on mitochondrial ROS generation and signalling [17-21]. In the present work, ROS also emerge as significant molecules involved in the signal transduction at the mitochondrial sub-cellular level. Inhibition of mitochondrial ROS generation by an anti-oxidant addition ( $ß$-carotene) reverses $\mathrm{CO}$ prevention of liver mitochondrial membrane permeabilization (Figure 4), which confirms their key role. Still one might hypothesize that ROS promote post-translational modifications on mitochondrial proteins, as described for ANT glutathionylation in non-synaptic mitochondria [21].

The most accepted hypothesis for CO-induced mitochondrial ROS production is via partial inhibition of cytochrome c oxidase, accumulating electrons at complex III level. The generated anion superoxide is rapidly converted into hydrogen peroxide [17]. According to our results, and using low concentrations of $\mathrm{CO}$ 


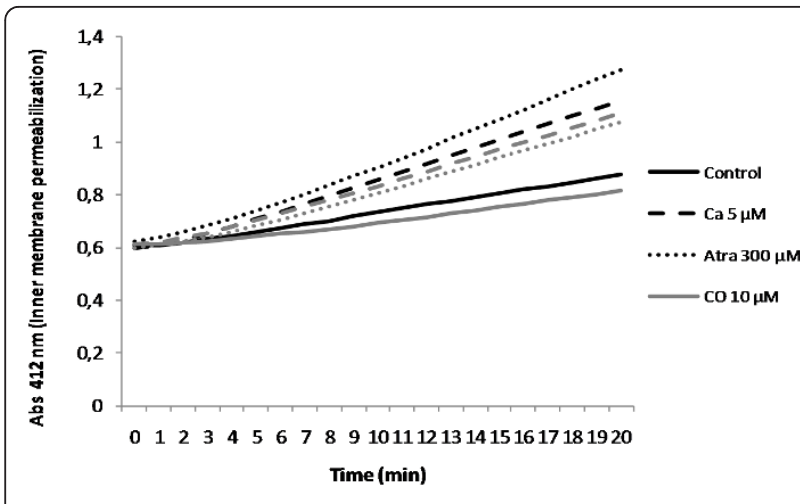

Figure 3 Carbon monoxide prevents inner membrane permeabilization. Citrate synthase activity assay was used to follow inner membrane permeabilization. Measurements were performed at $412 \mathrm{~nm}$ in the absence or presence of $10 \mu \mathrm{M}$ of $\mathrm{CO}$ and $5 \mu \mathrm{M}$ of $\mathrm{Ca}^{2+}$ or $300 \mu \mathrm{M}$ of atractyloside, at $37^{\circ} \mathrm{C}$ for 20 minutes.

Representative graphics of experiments, which were done in triplicates and repeated, at least, three times are shown.

$(10 \mu \mathrm{M})$, COX inhibition occurs only up to 10 minutes after $\mathrm{CO}$ treatment (Figure 5). One might speculate that this transient inhibition assures sufficient ROS generation to signal protective pathways, although not enough to induce damage. On the other hand, after 30 minutes COX activity is enhanced by CO treatment (Figure 5). Interestingly it is in accordance to our previous data showing an increase on ATP/ADP translocase activity of ANT [21] or a mitochondrial hyperpolarization by low concentrations of CO [20]. In summary, low doses of $\mathrm{CO}$ appear to accelerate mitochondrial oxidative phosphorylation and oxygen consumption. Another hypothesis to be considered is whether transient inhibition of COX activity also decreases calcium uptake protecting mitochondria against MMP.

Further studies are needed to elucidate the mechanisms implicated in ROS signalling, in particular how $\mathrm{CO}$ modifies and/or accelerates mitochondrial oxidative phosphorylation and oxygen consumption.

\section{Conclusions}

Thus, for the first time, it was demonstrated that $\mathrm{CO}$ inhibits MMP in isolated liver mitochondria, by preventing mitochondrial swelling, mitochondrial depolarization and the opening of a non-specific pore through inner membrane. Additionally, small amounts of ROS generation are essential for signalling MMP inhibition by $\mathrm{CO}$. In conclusion, it can be hypothesized that part of the CO's anti-apoptotic property in hepatocytes and/ or liver is due to its capacity to limit mitochondrial membrane permeabilization, preventing the release of pro-apoptotic factors into the cytosol.

\section{Methods}

\section{Isolation of mouse liver mitochondria}

Mitochondria were isolated from mouse liver (C57, female, 6-12 week old, Instituto Gulbenkian de Ciência, Portugal) by differential centrifugation and purified on Percoll gradient, according to [22]. Mitochondrial protein was quantified using BCA assay (Pierce, Illinois). All mitochondrial assays were performed under atmospheric air, without oxygen level control.

\section{Preparation of $\mathrm{CO}$ solution}

Fresh stock solutions of CO gas were prepared daily and carefully sealed immediately after. PBS (Phosphate Buffered Saline) was saturated by bubbling $100 \%$ of CO gas during 30 minutes to produce $10^{-3} \mathrm{M}$ stock solution. The concentration of $\mathrm{CO}$ in solution was determined spectrophotometrically, as previously described [23]. CO compressed gas at $100 \%$ was purchased from Linde, Germany.

\section{Measurement of ROS generation}

ROS generation was monitored by the conversion of 2',7'-dichlorofluorescein diacetate $\left(\mathrm{H}_{2} \mathrm{DCFDA}\right.$, Invitrogen, UK) to fluorescent 2', 7'-dichlorofluorescein (DCF). $25 \mu \mathrm{g}$ of mitochondrial protein was incubated with $5 \mu \mathrm{M}$ of $\mathrm{H}_{2}$ DCFDA and $10,50,100$ or $250 \mu \mathrm{M}$ of $\mathrm{CO}$ or $500 \mu \mathrm{M}$ of hydrogen peroxide, in swelling buffer. Fluorescence $\left(\lambda_{\text {exc }}: 485 \mathrm{~nm}, \lambda_{\text {em }}: 530 \mathrm{~nm}\right.$ ) was measured using Biotek Synergy 2 Spectrofluorimeter during 30 minutes at $37^{\circ} \mathrm{C}$. ROS generation was calculated as an increase over baseline levels, determined for untreated cells and considering $100 \%$ of ROS generation with $500 \mu \mathrm{M}$ of hydrogen peroxide. In some cases, $\beta$-carotene $(1 \mu \mathrm{M})$ was added to isolated mitochondria 10 minutes prior $\mathrm{CO}$ treatment.

\section{Swelling and depolarization assays}

$25 \mu \mathrm{g}$ of mitochondrial protein was diluted in swelling buffer for swelling (decrease in optical density at

Table 1 Carbon monoxide prevents inner membrane permeabilization

\begin{tabular}{|c|c|c|c|c|c|c|}
\hline & Control & $\mathrm{Ca}^{2+} 5 \mu \mathrm{M}$ & Atra $300 \mu \mathrm{M}$ & $\mathrm{CO} 10 \mu \mathrm{M}$ & $\mathrm{CO} 10 \mu \mathrm{M} \mathrm{Ca}{ }^{2+} 5 \mu \mathrm{M}$ & CO $10 \mu \mathrm{M}$ Atra $300 \mu \mathrm{M}$ \\
\hline Slope (Abs/min) & $0,00 E+00$ & $1,57 \mathrm{E}-02$ & $2,28 \mathrm{E}-02$ & $0,00 E+00$ & $1,34 \mathrm{E}-02$ & $1,27 E-02$ \\
\hline$\% \Delta$ Slope $(\mathrm{Abs} / \mathrm{min})$ relative to $\mathrm{Ca}^{2+}$ & 0,00 & $100,00 \pm 1,02$ & $145,13 \pm 1,20$ & 0,00 & $85,44 \pm 0,53$ & $81,25 \pm 0,46$ \\
\hline
\end{tabular}

Inner membrane permeabilization is followed by absorbance at $412 \mathrm{~nm}$. The slope was calculated between 10 to 20 minutes for each different condition in order to assess the effect of $\mathrm{CO}$ in the inner membrane permeabilization after treatment with $\mathrm{Ca}^{2+}$ or atractyloside. For slope calculation, absorbance values for each different condition were normalized by the absorbance value corresponding to the control non-treated mitochondria. The difference between control mitochondria and $\mathrm{Ca}^{2+}$-treated mitochondria slopes correspond to an increase of $100 \%$. 


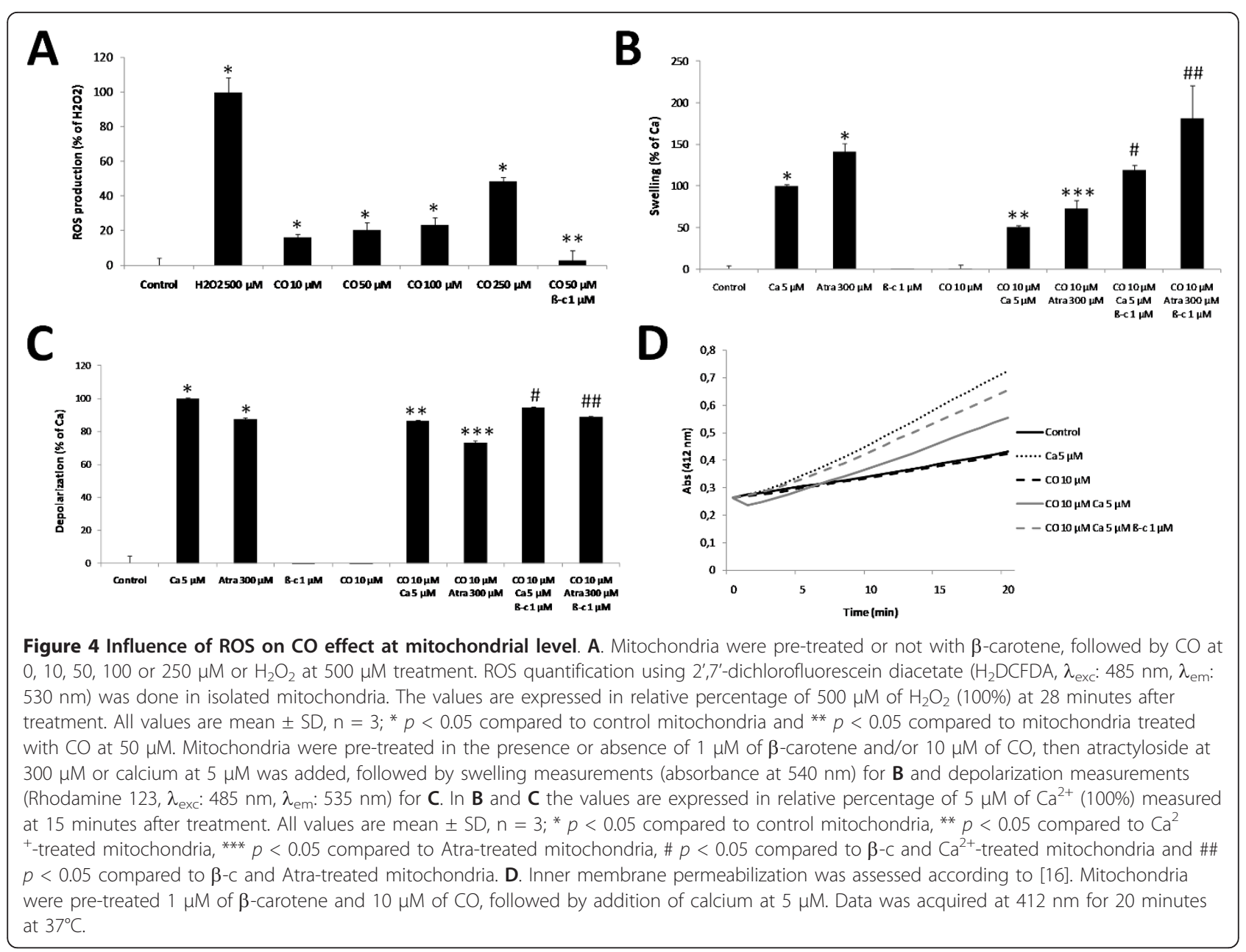

$540 \mathrm{~nm})$ or depolarization rhodamine $123(1 \mu \mathrm{M})$ fluorescence dequenching assay containing or not $10 \mu \mathrm{M}$ of $\mathrm{CO}$ for $15 \mathrm{~min}$ of incubation at room temperature, as described in [16]. In some cases, $\beta$-carotene $(1 \mu \mathrm{M})$ was added to isolated mitochondria 10 minutes prior $\mathrm{CO}$ treatment.

Mitochondrial swelling was assessed by the decrease in optical density at $540 \mathrm{~nm}$ measured for 30 minutes at $37^{\circ} \mathrm{C}$, using Biotek Synergy 2 Spectrofluorimeter. $100 \%$ of swelling is calculated based on the optical density decrease between non-treated and $12.5 \mu \mathrm{M} \mathrm{Ca}^{2+}$ or $300 \mu \mathrm{M}$ atractyloside treated mitochondria.
For depolarization assessment by Rhodamine 123 dequenching, $6.25 \mu \mathrm{M}$ of $\mathrm{Ca}^{2+}$ or $300 \mu \mathrm{M}$ of atractyloside were added. The fluorescent measurements $\left(\lambda_{\text {exc }}\right.$ : $485 \mathrm{~nm}, \lambda_{\text {em }}: 535 \mathrm{~nm}$, Biotek Synergy 2 Spectrofluorimeter) were followed at $37^{\circ} \mathrm{C}$ and are expressed in percentage relative to the positive control $5 \mu \mathrm{M}$ of $\mathrm{Ca}^{2+}$ or $300 \mu \mathrm{M}$ atractyloside $(100 \%)$ at the indicated time point, as described in [16].

\section{Inner membrane permeabilization assay}

Citrate synthase activity assay was used to assess the inner membrane permeability according to [16]. Upon inner mitochondrial membrane permeabilisation acetyl-

Table 2 Role of ROS in CO prevention of inner membrane permeabilization

\begin{tabular}{|c|c|c|c|c|c|}
\hline & Control & $\mathrm{Ca}^{2+} 5 \mu \mathrm{M}$ & $\mathrm{CO} 10 \mu \mathrm{M}$ & $\mathrm{CO} 10 \mu \mathrm{M} \mathrm{Ca}^{2+} 5 \mu \mathrm{M}$ & $\mathrm{CO} 10 \mu \mathrm{M} \mathrm{Ca}^{2+} 5 \mu \mathrm{M}$ B-c $1 \mu \mathrm{M}$ \\
\hline Slope (Abs/min) & $0,00 E+00$ & $1,78 \mathrm{E}-02$ & OOEO0 & $9,60 E-03$ & $1,34 \mathrm{E}-02$ \\
\hline$\% \Delta$ Slope $\left(\mathrm{Abs} / \mathrm{min}\right.$ ) relative to $\mathrm{Ca}^{2+}$ & 0,00 & $100,00 \pm 0,68$ & 0,00 & $53,79 \pm 0,56$ & $75,22 \pm 0,65$ \\
\hline
\end{tabular}

Inner membrane permeabilization is followed by absorbance at $412 \mathrm{~nm}$. The slope was calculated between 10 to 20 minutes for each different condition in order to assess the effect of $\mathrm{CO}$ in the inner membrane permeabilization in the presence or absence of $ß$-carotene and after treatment with $\mathrm{Ca}^{2+}$. For slope calculation, absorbance values for each different condition were normalized by the absorbance value corresponding to the control non-treated mitochondria. The difference between control mitochondria and $\mathrm{Ca}^{2+}$-treated mitochondria slopes correspond to an increase of $100 \%$. 


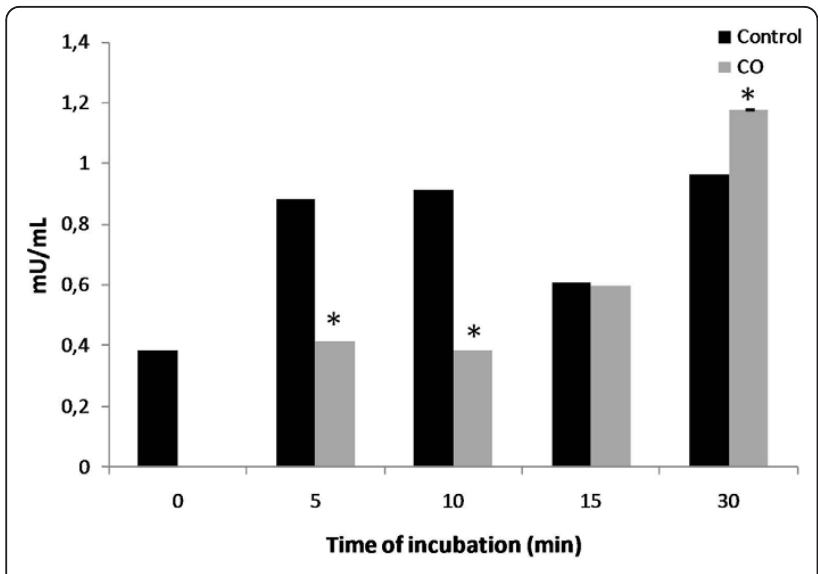

Figure 5 Carbon monoxide effect on cytochrome c oxidase activity. COX activity determinations were performed at $550 \mathrm{~nm}$, for 1 minute at $25^{\circ} \mathrm{C}$, after a treatment with $10 \mu \mathrm{M}$ of $\mathrm{CO}$ at $37^{\circ} \mathrm{C}$ for 5, 10, 15 and 30 minutes. For each sample, COX activity was determined and expressed in $\mathrm{mU} / \mathrm{mL}$. All values are mean $\pm \mathrm{SD}$, $\mathrm{n}=3$; * $p<0.05$ compared to control mitochondria.

CoA is able to enter into mitochondrial matrix, reacting with citrate synthase. 5, 5'-dithio-bis 2-nitrobenzoic acid (DTNB) and deacetyled acetyl-CoA reaction gives 5thio-2-nitrobenzoate (TNB) which can be followed by absorbance at $412 \mathrm{~nm}$. Briefly, $25 \mu \mathrm{g}$ of protein from isolated mitochondria was incubated with $\mathrm{CO}(10 \mu \mathrm{M})$ in swelling buffer containing $100 \mu \mathrm{M}$ of DTNB, $300 \mu \mathrm{M}$ of acetylCoA and $1 \mathrm{mM}$ of oxaloacetate. Inner membrane permeabilisation was induced by atractyloside at $300 \mu \mathrm{M}$ or $\mathrm{Ca}^{2+}$ at $5 \mu \mathrm{M}$. Whenever the case, $\beta$-carotene $(1 \mu \mathrm{M})$ was was added 10 minutes prior $\mathrm{CO}$ treatment. The absorbance at $412 \mathrm{~nm}$ was acquired for 20 minutes, using Biotek Synergy 2 Spectrofluorimeter. For slope calculation, absorbance values for each different condition were normalized by the absorbance value corresponding to the control non-treated mitochondria.

\section{Cytochrome c oxidase activity assay}

Cytochrome c oxidase (COX) activity was determined using a kit from Sigma CYTOCOX1. It is a colorimetric assay based on the oxidation of ferrocytochrome $\mathrm{c}$ to ferricytochrome c by COX. The reaction can be followed by a decrease in the absorbance at $550 \mathrm{~nm}$, at $25^{\circ} \mathrm{C}$. Briefly, mitochondria were treated with $10 \mu \mathrm{M}$ of $\mathrm{CO}$ at $37^{\circ} \mathrm{C}$ for $5,10,15$ and 30 minutes. The absorbance at $550 \mathrm{~nm}$ was acquired using Spectrophotometer DU-530, under the following conditions: $230 \mu \mathrm{g}$ of mitochondrial protein was incubated with $0.45 \mathrm{mM}$ Tris- $\mathrm{HCl}$ containing $12 \mathrm{mM}$ of sucrose, $9 \mathrm{mM}$ Tris- $\mathrm{HCl}$ containing $100 \mathrm{mM} \mathrm{KCl}$ and $0.01 \mathrm{mM}$ of ferrocytochrome $\mathrm{c}$, during 1 minute, with 10 seconds of interval. For each sample, COX activity was expressed in $\mathrm{mU} / \mathrm{mL}$.

\section{Statistical analysis}

Mitochondrial data is presented as a representative result of at least three independent batchs or assays. All values are mean $\pm S D, n \geq 3$. Error bars, corresponding to standard deviation, are represented in the figures. Statistical comparisons were performed using ANOVA: single factor, with $p<0.05, \mathrm{n} \geq 3 . p<0.05$ means that samples are significantly different at a confidence level of $95 \%$.

\section{List of Abbreviations}

$\mathrm{CO}$ : carbon monoxide; $\mathrm{HO}$ : heme-oxygenase; ROS: reactive oxygen species; MMP: mitochondrial membrane permeabilization; Atra: atractyloside; $\Delta \psi_{\mathrm{m}}$ : mitochondrial membrane potential; $\mathrm{H}_{2}$ DCFDA: 2',7'-dichlorofluorescein diacetate; $\beta$-c: $\beta$-carotene; RT: room temperature; COX: cytochrome $c$ oxidase

\section{Acknowledgements}

This work was supported by the Portuguese Fundação para a Ciência e Tecnologia grants PTDC/SAU-NEU/64327/2006 and PTDC/SAU-NEU/098747/ 2008. H. Vieira and C. Queiroga have grants from SFRH/BPD/27125/2006 and SFRH/BD/43387/2008. The authors express their gratitude to João Seixas from Alfama, Portugal, for measurements of $\mathrm{CO}$ in solution.

\section{Author details}

${ }^{1}$ Instituto de Biologia Experimental e Tecnológica (IBET), Apartado 12, 2781 901 Oeiras, Portugal. ${ }^{2}$ Instituto de Tecnologia Química e Biológica (ITQB), Universidade Nova de Lisboa, Apt 127, 2781-901, Oeiras, Portugal. ${ }^{3}$ INSERM U769 Université Paris-Sud, Faculté de Pharmacie, Châtenay Malabry, France.

\section{Authors' contributions}

CSFQ has made the acquisition and interpretation of data and drafted the manuscript; ASA performed experiments important for the re-estructure of the manuscript; PMA has been involved in revising the manuscript; $C B$ has made contributions to conception of the manuscript and to revise it critically and HLAV conceived of the study, participated in its design, coordination and acquisition of data, and helped to draft the manuscript. All authors read the paper and approved the final manuscript.

Received: 12 August 2010 Accepted: 9 March 2011

Published: 9 March 2011

\section{References}

1. Ryter SW, Alam J, Choi AM: Heme oxygenase-1/carbon monoxide: from basic science to therapeutic applications. Physiol Rev 2006, 86(2):583-650.

2. Soares MP, Bach FH: Heme oxygenase-1: from biology to therapeutic potential. Trends in molecular medicine 2009, 15(2):50-58.

3. Tsui TY, Siu YT, Schlitt HJ, Fan ST: Heme oxygenase-1-derived carbon monoxide stimulates adenosine triphosphate generation in human hepatocyte. Biochemical and biophysical research communications 2005, 336(3):898-902.

4. Tsui TY, Obed A, Siu YT, Yet SF, Prantl L, Schlitt HJ, Fan ST: Carbon monoxide inhalation rescues mice from fulminant hepatitis through improving hepatic energy metabolism. Shock (Augusta, Ga 2007, 27(2):165-171.

5. Zuckerbraun BS, Billiar TR, Otterbein SL, Kim PK, Liu F, Choi AM, Bach FH, Otterbein LE: Carbon monoxide protects against liver failure through nitric oxide-induced heme oxygenase 1. J Exp Med 2003, 198(11):1707-1716.

6. Choi BM, Pae HO, Kim YM, Chung HT: Nitric oxide-mediated cytoprotection of hepatocytes from glucose deprivation-induced cytotoxicity: involvement of heme oxygenase-1. Hepatology (Baltimore, Md 2003, 37(4):810-823.

7. Sarady JK, Zuckerbraun BS, Bilban M, Wagner O, Usheva A, Liu F, Ifedigbo E, Zamora R, Choi AM, Otterbein LE, et al: Carbon monoxide protection against endotoxic shock involves reciprocal effects on iNOS in the lung and liver. Faseb J 2004, 18(7):854-856, Epub 2004 Mar 2004. 
8. Conde de la Rosa L, Vrenken TE, Hannivoort RA, Buist-Homan M, Havinga R, Slebos DJ, Kauffman HF, Faber KN, Jansen PL, Moshage H: Carbon monoxide blocks oxidative stress-induced hepatocyte apoptosis via inhibition of the p54 JNK isoform. Free radical biology \& medicine 2008, 44(7):1323-1333.

9. Kim HS, Loughran PA, Rao J, Billiar TR, Zuckerbraun BS: Carbon monoxide activates NF-kappaB via ROS generation and Akt pathways to protect against cell death of hepatocytes. American journal of physiology 2008, 295(1):G146-G152.

10. Kim HS, Loughran PA, Kim PK, Billiar TR, Zuckerbraun BS: Carbon monoxide protects hepatocytes from TNF-alpha/Actinomycin D by inhibition of the caspase-8-mediated apoptotic pathway. Biochemical and biophysical research communications 2006, 344(4):1172-1178.

11. Kroemer G, Galluzzi L, Brenner C: Mitochondrial membrane permeabilization in cell death. Physiol Rev 2007, 87(1):99-163.

12. Galluzzi L, Blomgren K, Kroemer G: Mitochondrial membrane permeabilization in neuronal injury. Nat Rev Neurosci 2009, 10(7):481-494.

13. Belzacq AS, Vieira HL, F V, Vandecasteele G, Cohen I, Prevost MC, Larquet E, Pariselli F, Petit PX, Kahn A, et al: Bcl-2 and Bax modulate adenine nucleotide translocase activity. Cancer Res 2003, 63(2):541-546.

14. Marzo I, Brenner C, Zamzami N, Jurgensmeier JM, Susin SA, Vieira HL, Prevost MC, Xie Z, Matsuyama S, Reed JC, et al: Bax and adenine nucleotide translocator cooperate in the mitochondrial control of apoptosis. Science 1998, 281(5385):2027-2031.

15. Vieira HL, Haouzi D, El Hamel C, Jacotot E, Belzaca AS, Brenner C, Kroemer G: Permeabilization of the mitochondrial inner membrane during apoptosis: impact of the adenine nucleotide translocator. Cell Death Differ 2000, 7(12):1146-1154.

16. Belzacq-Casagrande AS, Martel C, Pertuiset C, Borgne-Sanchez A, Jacotot E, Brenner C: Pharmacological screening and enzymatic assays for apoptosis. Front Biosci 2009, 14:3550-3562.

17. Bilban M, Haschemi A, Wegiel B, Chin BY, Wagner O, Otterbein LE: Heme oxygenase and carbon monoxide initiate homeostatic signaling. $J \mathrm{Mol}$ Med 2008, 86(3):267-279.

18. D'Amico G, Lam F, Hagen T, Moncada S: Inhibition of cellular respiration by endogenously produced carbon monoxide. J Cell Sci 2006, 119(Pt 11):2291-2298.

19. Vieira HL, Queiroga CS, Alves PM: Preconditioning induced by Carbon Monoxide provides neuronal protection against Apoptosis. Journal of neurochemistry 2008, 107:375-384.

20. Zuckerbraun BS, Chin BY, Bilban M, de Costa d'Avila J, Rao J, Billiar TR, Otterbein LE: Carbon monoxide signals via inhibition of cytochrome $c$ oxidase and generation of mitochondrial reactive oxygen species. Faseb J 2007, 21(4):1099-1106.

21. Queiroga CS, Almeida AS, Martel C, Brenner C, Alves PM, Vieira HL: Glutathionylation of adenine nucleotide translocase induced by carbon monoxide prevents mitochondrial membrane permeabilisation and apoptosis. The Journal of biological chemistry 2010, 285(22):17077-17088.

22. Vieira HL, Boya P, Cohen I, El Hamel C, Haouzi D, Druillenec S, Belzaca AS, Brenner C, Roques B, Kroemer G: Cell Permeable BH3-Peptides Overcome the Cytoprotective Effect of Bcl-2 and Bcl-XL. Oncogene 2002, 21:1963-1977.

23. Motterlini R, Clark JE, Foresti R, Sarathchandra P, Mann BE, Green CJ: Carbon monoxide-releasing molecules: characterization of biochemical and vascular activities. Circ Res 2002, 90(2):E17-24.

doi:10.1186/1471-2121-12-10

Cite this article as: Queiroga et al: Carbon monoxide prevents hepatic mitochondrial membrane permeabilization. BMC Cell Biology 2011 12:10.

\section{Submit your next manuscript to BioMed Central and take full advantage of:}

- Convenient online submission

- Thorough peer review

- No space constraints or color figure charges

- Immediate publication on acceptance

- Inclusion in PubMed, CAS, Scopus and Google Scholar

- Research which is freely available for redistribution 